\title{
Development in Assay Methods for in Vitro Antimalarial Drug Efficacy Testing: A Systematic Review
}

OPEN ACCESS

Edited by:

Ajay Sharma,

Chapman University, United States

Reviewed by:

Tarun Kumar Bhatt,

Central University of Rajasthan, India

Simone Brogi,

University of Siena, Italy

${ }^{*}$ Correspondence:

Bikash Medh

drbikashus@yahoo.com;

drbikashmedhi@gmail.com

Specialty section:

This article was submitted to

Experimental Pharmacology and Drug

Discovery,

a section of the journal

Frontiers in Pharmacology

Received: 03 February 2017

Accepted: 04 October 2017

Published: 23 October 2017

Citation:

Sinha S, Sarma P, Sehgal $R$ and

Medhi B (2017) Development

in Assay Methods for in Vitro Antimalarial Drug Efficacy Testing:

A Systematic Review.

Front. Pharmacol. 8:754

doi: 10.3389/fphar.2017.00754

\author{
Shweta Sinha ${ }^{1}$, Phulen Sarma ${ }^{2}$, Rakesh Sehgal ${ }^{1}$ and Bikash Medhi ${ }^{2 *}$ \\ ${ }^{1}$ Department of Medical Parasitology, Postgraduate Institute of Medical Education and Research, Chandigarh, India, \\ ${ }^{2}$ Department of Pharmacology, Postgraduate Institute of Medical Education and Research, Chandigarh, India
}

The emergence and spread of drug resistance are the major challenges in malaria eradication mission. Besides various strategies laid down by World Health Organization, such as vector management, source reduction, early case detection, prompt treatment, and development of new diagnostics and vaccines, nevertheless the need for new and efficacious drugs against malaria has become a critical priority on the global malaria research agenda. At several screening stages, millions of compounds are screened (1,000-2,000,000 compounds per screening campaign), before pre-clinical trials to select optimum lead. Carrying out in vitro screening of antimalarials is very difficult as different assay methods are subject to numerous sources of variability across different laboratories around the globe. Despite this, in vitro screening is an essential part of antimalarial drug development as it enables to resource various confounding factors such as host immune response and drug-drug interaction. Therefore, in this article, we try to illustrate the basic necessity behind in vitro study and how new methods are developed and subsequently adopted for high-throughput antimalarial drug screening and its application in achieving the next level of in vitro screening based on the current approaches (such as stem cells).

Keywords: malaria, in vitro, assay method, HTS, stem cells

\section{INTRODUCTION}

Malaria is known for millennium for causing fatal consequences. Basically, it is caused by five different species of Plasmodium namely falciparum, vivax, malariae, ovale, and knowlesi. According to WHO there were 214 million cases of malaria across the world in the year 2015. Although the incidence and mortality decreased by 37 and $60 \%$, respectively, globally between the years

Abbreviations: APAD, 3-acetylpyridine adenine dinucleotide; CD34+, cluster of Differentiation 34; CD71, cluster of Differentiation 71; CD81, cluster of Differentiation 81; DAPI, 4, 6-diamidino-2-phenylindole; DELI, double-site enzymeLinked LDH immunodetection; DHS, deoxyhypusine synthase; DMSO, dimethyl sulfoxide; DOHH, deoxyhypusine hydroxylase; EEFs, exoerythrocytic forms; FPH1, functional proliferation of primary hepatocytes 1; FT-IR, Fourier transform infrared; hLDH, human lactate dehydrogenase; HPLC, high-performance liquid chromatography; HRP-II, histidine-rich protein II; HRP-II ELISA histidine-rich protein II enzyme-linked immunosorbent assay; HSC, hematopoietic stem cells; HTS, high throughput screening; $\mathrm{IC}_{50}$, half maximal inhibitory concentration; iHLCs, induced hepatocyte like cells; iPSCs, induced pluripotent stem cells; MMV, Medicines for Malaria Venture; NAD, nicotinamide adenine dinucleotide; PB-PK, physiologically based pharmacokinetic; PK-PD, pharmacokinetic/pharmacodynamic; pLDH, parasite lactate dehydrogenase; PRISMA, preferred reporting items for systematic reviews and meta-analyses; SRB1, scavenger receptor class B type I; Tris-HCL/SDS, tris hydrochloride/sodium dodecyl sulfate; WHO, World Health Organization. 
2000 and 2015 (WHO, 2016) because of the continuous tremendous effort in the malaria eradication program and various other strategies, still more attention is required to obscure resistance phenomena of the diseases (Hyde, 2007; Sinha et al., 2014). Out of the various strategies to control over malaria cases, drug development organizations are also trying to develop a better, more efficacious and safe drug. Each year, thousands and thousands of moieties are screened for their antimalarial activity, but very few of them are capable of entering the market. Developing a whole new drug from a basic idea is so complex that it takes around 12-15 years and costs more than $\$ 1$ billion till the launch of a new drug as a finished product in the market (Hughes et al., 2011). Recently, more emphasis is given to discovering new antimalarial drugs as a result of higher prevalence of resistance to most of the known antimalarial drugs in Southeast Asian countries (Noedl et al., 2008; Dondorp et al., 2009; Phyo et al., 2012) and to overcome this situation various academic as well as non-profit institutions are signing agreement with major pharmaceutical industry to develop some new antimalarial drugs. Moreover, there are few new antimalarial agents that are under clinical trial procedures and many of these agents are those which were resurrected from earlier antimalarial drug discovery programs (Gelb, 2007). Nowadays, the main challenge in drug discovery procedure is to streamline the whole method to reduce the manpower, total mechanistic energy and cost consumption, which begins with screening of thousands of compounds at in vitro level, which will reduce the burden at in vivo level and finally decrease the number of animals used for in vivo screening. Many variations in the in vitro antimalarial assay methods from the year 1968 to till date have arisen from a very basic concept called "macrotechnique" (Rieckmann et al., 1968). Subsequently, with advancement in knowledge regarding parasite biology, material science, and technology, there are a number of in vitro antimalarial assay methods that are used to screen antimalarials acting not only at the erythrocytic stage but also at the liver stage and the gametocyte stages. Most of these in vitro efficacy models assist us with direct knowledge toward any potential new drug/disease, serendipitous identification of new moieties in less time with minimum accountability and enable to determine antimalarial resistance patterns (Fidock et al., 2004). Also, screening of compounds in vitro in whole parasite assays is desirable as it helps in effective penetration of compound inside cellular membranes of the parasite to a measurable extent, which gives a strong basis for drug discovery by mimicking the in vivo situation (Hernandez et al., 2006; Hobbs and Duffy, 2011). However, because of the trend of adopting independent approaches by various research laboratories for developing their own assays, it often results in many variations relating to laboratory-practices, assays, and data-related variables. Therefore, it is recommended to screen new compounds applying multiple technologies to minimize or overcome these variations (Lucantoni et al., 2017). Therefore, in this article we try to illustrate the basic necessity behind in vitro study and how new methods are developed and subsequently adopted for high throughput antimalarial drug screening and its application in achieving the next level of in vitro screening based on the current approaches (such as stem cells).

\section{MATERIALS AND METHODS}

An electronic systematic literature search was accomplished to find all relevant studies in PubMed, EMBASE and Google Scholar starting from the year 1968 to till date. The search keywords and phrases included, In vitro models for antimalarial efficacy, antimalarial assay methods, antimalarial drug sensitive assay, In vitro efficacy models for Plasmodium and high throughput antimalarial drug screening. All in vitro methods that were mostly used for compound/drug screening/drug susceptibility testing were included in the study. However, studies involving in vitro methods for the clinical diagnosis such as rapid diagnostic techniques, Raman spectroscopy and HTS methods for other parasites were excluded. Unpublished data and thesis work were also excluded. For eliminating duplicity the title and abstract of all searched studies were examined twice and the reference lists of the selected articles were additionally reviewed for more relevant studies.

\section{RESULTS}

After a thorough search of PubMed, EMBASE and Google Scholar, a total of 612 studies relevant to the assumed idea were retrieved. Among these, only 61 articles having appropriate content and those that fulfilled the inclusion and exclusion criteria were further selected for writing this review (Figure 1, Liberati et al., 2009).

\section{DISCUSSION}

Malaria parasite displays a complex life cycle which is intermediate between two hosts, a female Anopheles mosquito, which carries sporozoites in its salivary gland and later injects it into the human being while taking a blood meal. The next stage of malaria parasite begins with in the human being; it is divided into two phases that is, the pre-erythrocytic (exoerythrocytic) phase and the erythrocytic phase. It takes less than a minute for sporozoites to invade liver cells through blood circulation after being inoculated. Inside the liver cells, sporozoites transform into multi-nucleated schizonts. After that, these schizont releases thousands of merozoites (exoerythrocytic schizogony) into the peripheral circulation which is responsible for most of the clinical symptoms in the affected population. Understanding the parasite life cycle, parasite biology, and pathophysiology of the disease is the basic to know before any drug discovery effort. Drug efficacy test at in vitro level is the most preliminary step for screening any new compound libraries (Figure 2). Rieckmann et al. (1968) developed simple in vitro susceptibility tests called "macrotechnique" with an objective to find and follow the trend of evolution of chloroquine-resistant Plasmodium falciparum in several parts of the world. The method involves counting of schizonts in test vials with a comparison to drug-free controls and only because of its simplicity a standard test kit and a standard procedure, known as "WHO standard macrotest," were established under the sponsorship of WHO. However, because 


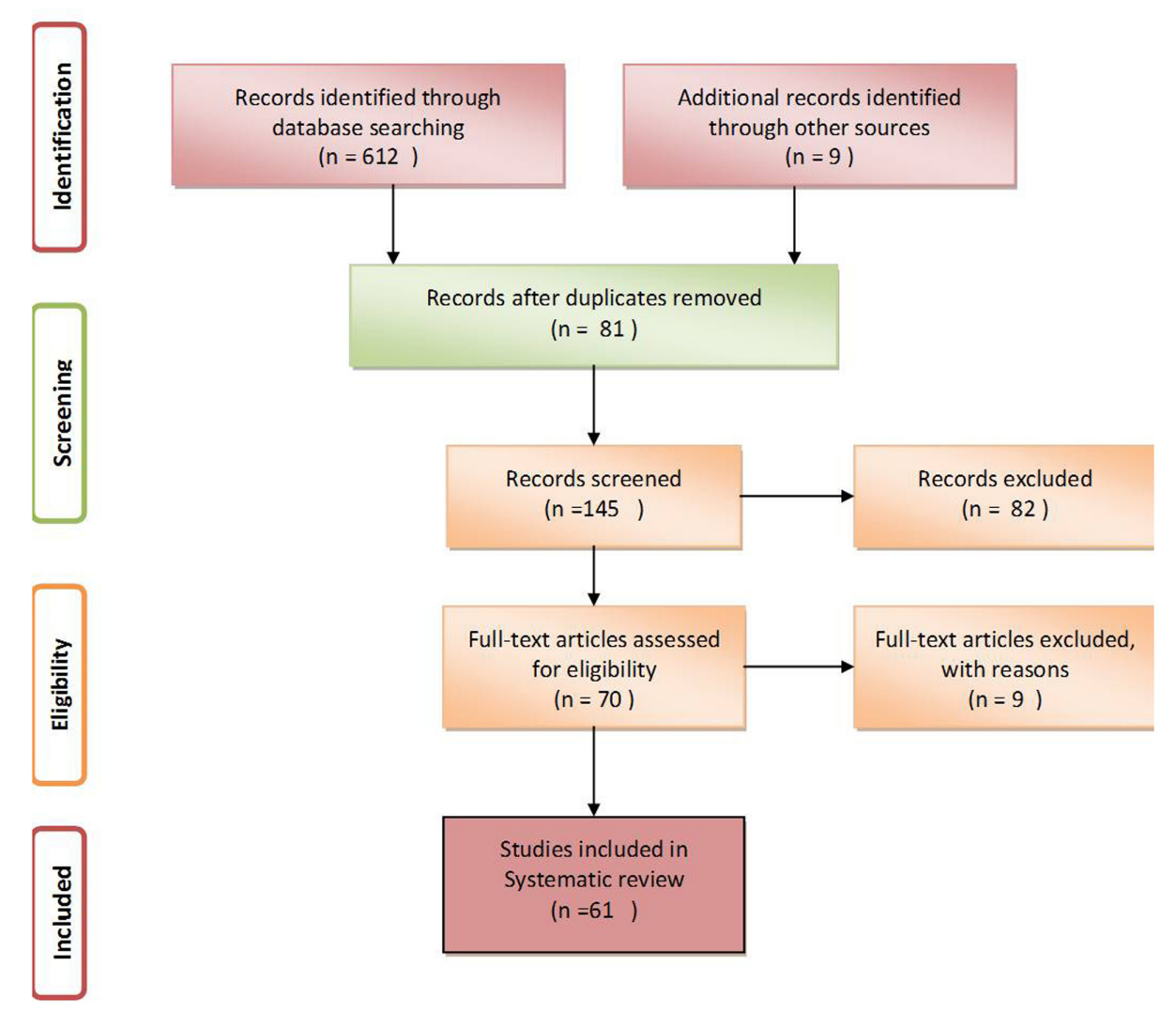

FIGURE 1 | Schematic flow diagram to show selection criteria for systematic review.

of less reproducibility in the data, the assay was abandoned in the late 1980s (Rieckmann et al., 1968; Basco, 2007). Trager and Jensen (1976) illustrated a new in vitro method for continuous cultivation of $P$. falciparum, and with the introduction of this method, substantial modification in the principle of the previous practicing in vitro culture technique was undertaken (Table 1). Also, this modified technique seems to be pioneered in establishing the base of many in vitro drug susceptibility assays for screening thousands of drug moieties.

\section{SCHIZONT COUNTING BASED ON SIMPLE MICROSCOPY}

After a series of modifications in $48 \mathrm{~h}$ variant test, Rieckmann et al. (1978) developed "Microtest". Briefly, after preparation of thick blood smears from each well, the total number of schizonts in each well was counted against 500 leukocytes. Finally, in vitro activity was demonstrated as the percentage of the total counted schizonts at each drug concentration, with regard to the total counted schizonts in drug-free controls. Fingerprick capillary blood samples are sufficient to do this test. After that, the technique was later adopted to design a field-relevant microtest, under the sponsorship of WHO by Wernsdorfer and Kouznetsov (1980), Wernsdorfer and Payne (1988). Basically, macrotest and microtest are the two earlier WHO assay systems that are designed for using as laboratory tools to assist in surveillance and description regarding the epidemiology of drug-resistant malaria as part of the global monitoring program. These assay systems are used to follow the evolution pattern of drug resistance parasite and can also be used for determining the baseline levels of malaria drug sensitivity. On the basis of the above two protocols, Mark I, Mark II, and Mark III were developed between 1981 and 2000 which is known by "WHO standard in vitro Microtest kit" (Basco, 2007).

\section{ASSAY BASED ON RADIOISOTOPES}

During malaria parasite culture, platelets and uninfected erythrocytes in the culture plate do not synthesize their RNA, DNA, proteins or any of their membranes. Also, leukocytes are unable to multiply and hence disintegrate within a certain period of time. So, among all these, only malaria parasites have actively dividing cells. Hence, the addition of radioactive substances into the culture media enables the parasites to incorporate radioactive precursors themselves, which seems to be a sensitive indirect measurement assay for the parasite metabolic activity. Another beneficial thing is the reliability of Plasmodium sp. to use exogenous purines as they are unable to synthesize purines de novo (Sherman, 1977). Among radioisotopes, $\left[{ }^{3} \mathrm{H}\right]$ hypoxanthine is the most preferred radioisotope for antimalarial 


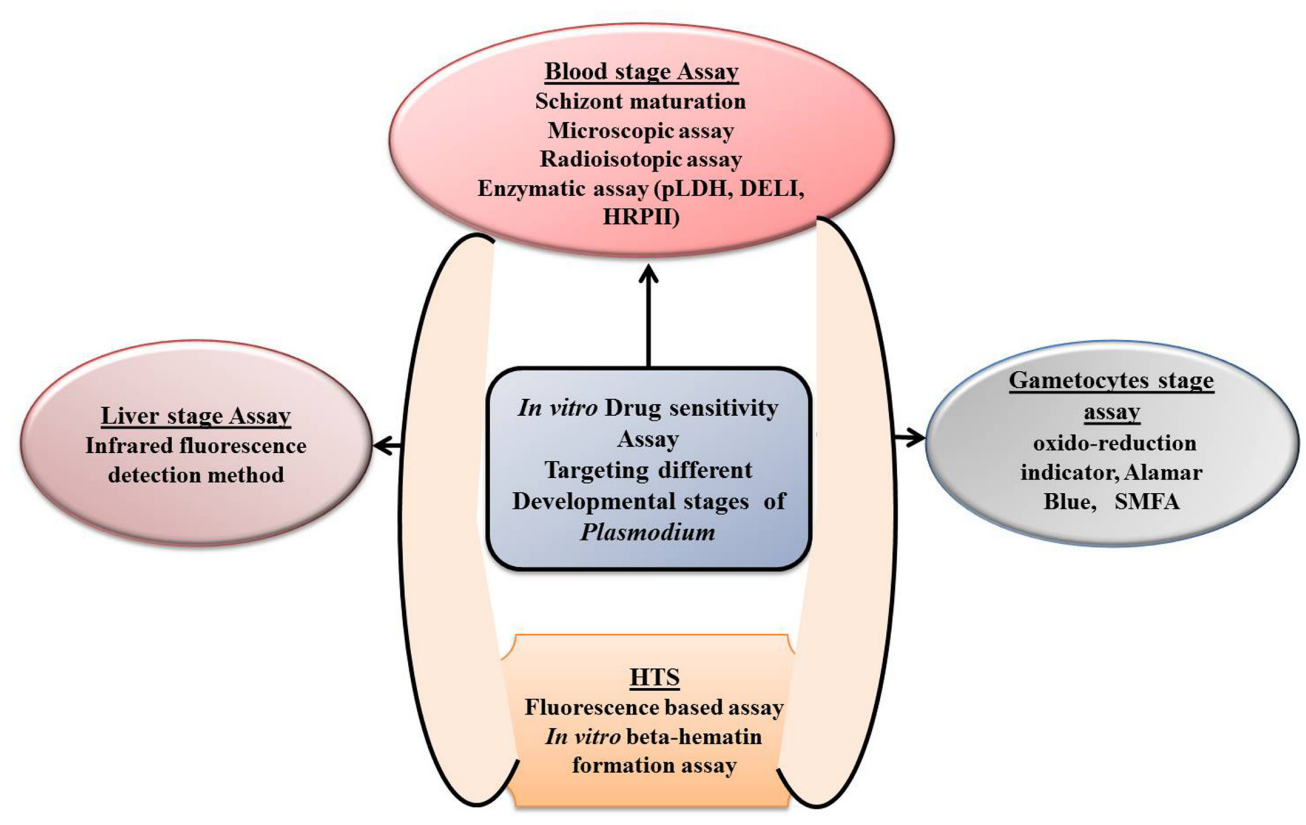

FIGURE 2 | Depiction of different in vitro drug sensitivity assays targeting different development stages of Plasmodium.

in vitro drug sensitivity assays as it is also the main purine base needed by $P$. falciparum. During this assay, under normal conditions, incorporation of $\left[{ }^{3} \mathrm{H}\right]$ hypoxanthine is directly related to the count of $P$. falciparum-infected erythrocytes and the initial parasitemia required for this assay is between 0.1 and $1.0 \%$ at $1.5 \%$ hematocrit during $42 \mathrm{~h}$ of incubation (Chulay et al., 1983; Geary et al., 1983). Radiolabeled precursors of phospholipids, such as the sources of phospholipid polar head groups, $\left[{ }^{3} \mathrm{H}\right]$ ethanolamine were incorporated by Elabbadi et al. (1992); $\left[{ }^{3} \mathrm{H}\right]$ ethanolamine is another radioisotope used for similar assay. However, incorporation was observed more with $\left[{ }^{3} \mathrm{H}\right]$ ethanolamine into infected erythrocytes as compared with $\left[{ }^{3} \mathrm{H}\right]$ hypoxanthine. During drug sensitivity assay both $\left[{ }^{3} \mathrm{H}\right]$ ethanolamine and $\left[{ }^{3} \mathrm{H}\right]$ hypoxanthine incorporation increases linearly at starting parasitemia in between 0.1 and $1 \%$ with haematocrit levels of $0.1-3 \%$. Both these radioisotope precursors exhibit distinct metabolic activities and the findings suggest that, $\left[{ }^{3} \mathrm{H}\right]$ ethanolamine can be a better substitute for $\left[{ }^{3} \mathrm{H}\right]$ hypoxanthine to assess parasite viability. Also, similar responses under in vitro conditions with $P$. falciparum reference clone were obtained when $\left[{ }^{3} \mathrm{H}\right]$ ethanolamine radioisotope assay was compared with SYBR Green I-based fluoroassay (Smilkstein et al., 2004). The first radioisotope, semi-automated assay was that of Desjardins et al. (1979). The method was primarily adopted for drug screening in the United States Army Antimalarial Drug Development Program at the Walter Reed Army Institute of Research (Washington, DC, United States) and presently considered as the "gold standard" for various in vitro drug sensitivity assays. The assay involves the use of liquid scintillation counter for quantification of incorporated $\left[{ }^{3} \mathrm{H}\right]$ hypoxanthine. This assay method is now widely used in well-equipped laboratories and has also been adapted for studying epidemiology on fresh clinical isolates (Basco, 2007). Also, this assay is supposed to be a reference method in most of the advanced countries for assaying drug sensitivity; however, the same is not a reference method in most of the malaria-endemic countries (Basco, 2007). Stringent regulations regarding handling and disposal of radioactive material since the late 1970s and requirement of approximately $0.5 \%$ of parasitemia along with the compulsion to use highly expensive instruments, such as liquid scintillation counters, limit the test application for applying under field conditions (Noedl et al., 2003a). All these situations necessitate the use of non-radioactive methods as a standard method in near future.

\section{ENZYME-BASED ASSAY}

Parasite lactate dehydrogenase is an important terminal enzyme of the glycolytic pathway in Plasmodium parasite and thus plays a vital role in anaerobic carbohydrate metabolism (Makler et al., 1993). Plasmodium chiefly depends on anaerobic glycolysis, and for this they need regeneration of NAD to get a continuous flux of glucose through this pathway (Sherman, 1998). As an enzyme structure of $\mathrm{pLDH}$ is morphologically different from host LDH, so its production and accumulation are used as indices for checking parasite viability (Sherman, 1961; Makler et al., 1993; Brown et al., 2004). Hence, a drug-sensitivity assay, which displays inhibitory profiles of parasite metabolic activity through estimation of enzyme pLDH was developed by Makler and Hinrichs (1993). The assay is rooted on monitoring the ability of LDH enzyme to quickly use a coenzyme, APAD which is a NAD analog, in reaction, that converts lactate into pyruvate. However, LDH of the host erythrocytes carries out the same 
TABLE 1 | Different in vitro drug sensitivity assays used in antimalarial drug screening.

\begin{tabular}{|c|c|c|c|c|c|}
\hline $\begin{array}{l}\text { In vitro efficacy } \\
\text { models }\end{array}$ & $\begin{array}{l}\text { Introductory } \\
\text { year }\end{array}$ & Advantages & Disadvantages & Reliability/sensitivity & Reference \\
\hline Macrotechnique & 1968 & $\begin{array}{l}\text { - Simple, } \\
\text { - Does not require } \\
\text { sophisticated equipment } \\
\text { - Reliable for field } \\
\text { application }\end{array}$ & $\begin{array}{l}\text { - Need for } 10 \mathrm{ml} \text { of venous } \\
\text { blood } \\
\text { - Low success rate }(<70 \%)\end{array}$ & $\begin{array}{l}\text { - A parasite count of } \\
\text { between } 1000 \text { and } \\
80,000 \text { asexual parasites } \\
\text { per } \mu \text { l } \\
\text { - Less reliable with poor } \\
\text { sensitivity }\end{array}$ & Rieckmann et al., 1968 \\
\hline $\begin{array}{l}\text { Semiautomated } \\
\text { microdilution technique } \\
\text { or isotopic assays } \\
\text { (radiolabeled } \\
\text { hypoxanthine } \\
\text { incorporation assay) }\end{array}$ & 1979 & $\begin{array}{l}\text { - A rapid and quantitative } \\
\text { measurement of } \\
\text { antimalarial activity } \\
\text { - Automatic reading } \\
\text { - Reduces the chance of } \\
\text { result variability }\end{array}$ & $\begin{array}{l}\text { - Expensive } \\
\text { - Time consuming } \\
\text { - Multiple processing steps } \\
\text { - Special handling and } \\
\text { requirement of waste } \\
\text { disposal system } \\
\text { - Requirement for a } \\
\text { relatively high (i.e., } \geq 0.1 \%) \\
\text { starting parasitemia } \\
\text { - Inappropriate for field } \\
\text { application } \\
\text { - Requirement of } \\
\text { instrument such as liquid } \\
\text { scintillation counters and } \\
\text { harvesting machines }\end{array}$ & $\begin{array}{l}\text { - Reliability and sensitivity } \\
\text { are moderate }\end{array}$ & $\begin{array}{l}\text { Desjardins et al., 1979; } \\
\text { Chulay et al., } 1983 .\end{array}$ \\
\hline $\begin{array}{l}\text { Autometric flow } \\
\text { cytometeric analysis }\end{array}$ & 1990 & $\begin{array}{l}\text { - Fast } \\
\text { - Automated } \\
\text { - Accurate } \\
\text { - Ability to differentiate } \\
\text { between other parasite } \\
\text { stages } \\
\text { - Yields more information } \\
\text { within one single analysis }\end{array}$ & $\begin{array}{l}\text { - Expensive } \\
\text { - Requirement of } \\
\text { instrument }\end{array}$ & $\begin{array}{l}\text { - Moderate reliability with } \\
\text { high sensitivity }\end{array}$ & $\begin{array}{l}\text { van Vianen et al., 1990; } \\
\text { van Vianen et al., } 1993\end{array}$ \\
\hline $\begin{array}{l}\text { Lactate dehydrogenase } \\
(\mathrm{pLDH}) \text { assay }\end{array}$ & 1993 & $\begin{array}{l}\text { - Fast } \\
\text { - Reproducible } \\
\text { - Automated with little data } \\
\text { variability } \\
\text { - No need of trained } \\
\text { personnel }\end{array}$ & $\begin{array}{l}\text { - Less applicable for field } \\
\text { application } \\
\text { - Need of initial parasitemia } \\
\text { of } 1-2 \%\end{array}$ & - Reliable and very sensitive & Makler et al., 1993 \\
\hline $\begin{array}{l}\text { Double-site } \\
\text { enzyme-linked lactate } \\
\text { dehydrogenase enzyme } \\
\text { immunodetection } \\
\text { (DELI) assay }\end{array}$ & 2001 & $\begin{array}{l}\text { - Easier to perform } \\
\text { - Faster to implement } \\
\text { - No trained personnel } \\
\text { needed } \\
\text { - Reliable for field } \\
\text { application } \\
\text { - Cheaper than in vitro } \\
\text { isotopic assays }\end{array}$ & $\begin{array}{l}\text { - Expensive } \\
\text { - Requirement of } \\
\text { monoclonal antibody } \\
\text { - Not reliable for field } \\
\text { application }\end{array}$ & $\begin{array}{l}\text { - Highly reliable and very } \\
\text { sensitive to detect low } \\
\text { parasitemia }(0.005 \%)\end{array}$ & $\begin{array}{l}\text { Brasseur et al., 2001; } \\
\text { Druilhe et al., } 2001\end{array}$ \\
\hline $\begin{array}{l}\text { Histidine-rich protein II } \\
\text { (HRPII) drug } \\
\text { susceptibility assay }\end{array}$ & 2002 & $\begin{array}{l}\text { - Fast } \\
\text { - Simple to establish } \\
\text { - Highly reproducible }\end{array}$ & $\begin{array}{l}\text { - Time consuming as it } \\
\text { uses a longer culture time } \\
\text { (72 h) }\end{array}$ & - Reliable and very sensitive & Noedl et al., 2002 \\
\hline
\end{tabular}


TABLE 1 | Continued

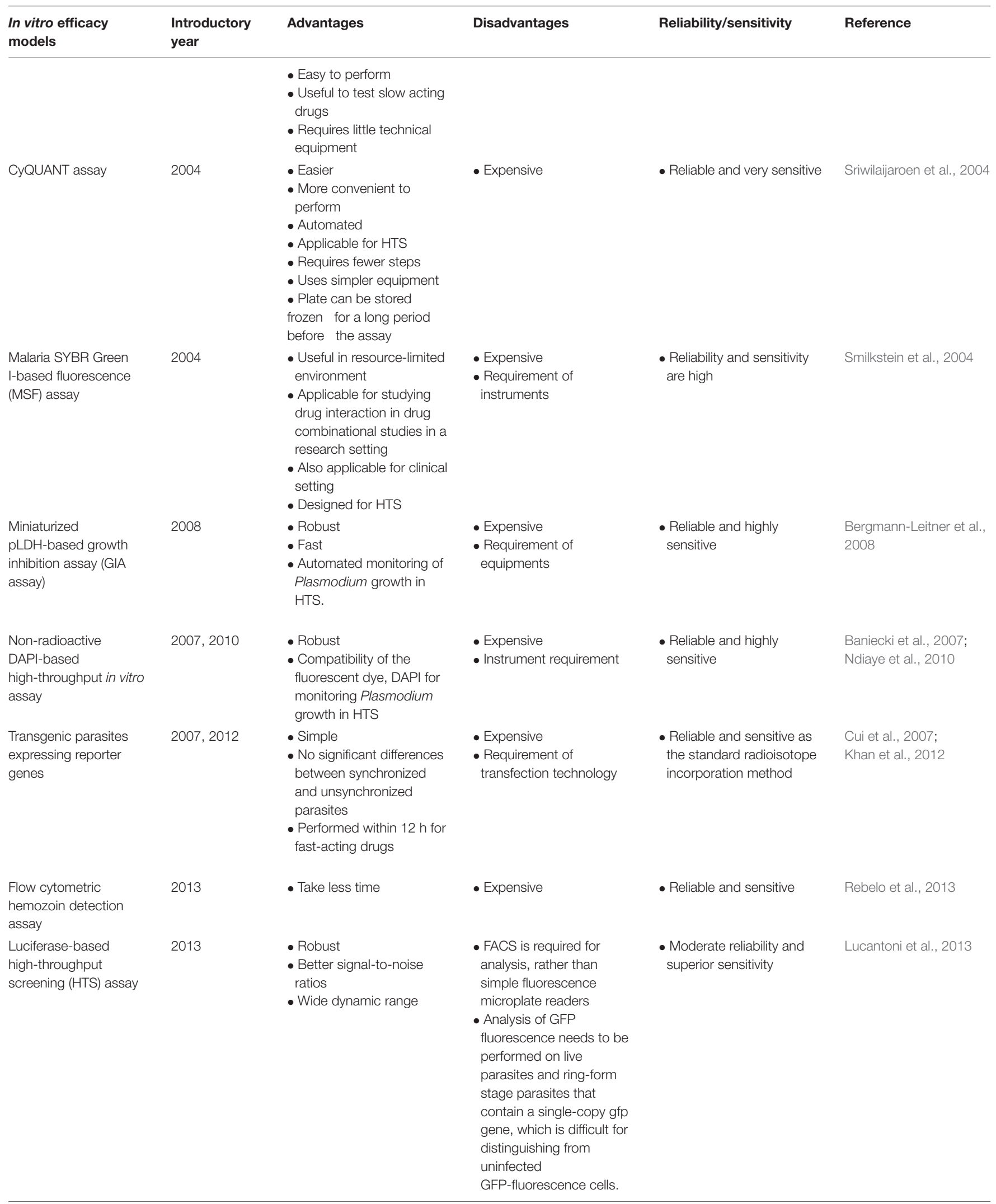


reaction at a very slow pace in the presence of $A P A D$. In the assay, development of reduced APAD (APADH) is measured, which interprets a direct correlation between parasitemia level and pLDH activity (Makler and Hinrichs, 1993; Makler et al., 1993; Basco et al., 1995). Because of limitations such as the requirement of high parasite densities of $1-2 \%$ and insensitivity for field applications, a DELI assay was developed, which was based on monoclonal antibodies specific for $\mathrm{pLDH}$ and this assay was found to be applicable for both diagnostic and drugsensitivity testing. The technique is highly sensitive as it can detect the parasite at very low level of parasitemia $(<0.005 \%)$. However, because of limited availability of monoclonal antibodies specific to the $\mathrm{pLDH}$, it has limited its application (Nogueira, 2010). The other, assay is based on water-soluble, histidine and alanine rich proteins, that is, HRP II which is mostly localized in various cellular compartments of parasite including cytoplasm (Howard et al., 1986). This assay is at least 10 times more sensitive than the other isotopic assays with minor technical requirements. The method involves measurement of HRP II levels, which is directly associated with parasite density and its growth (Desakorn et al., 1997; Noedl et al., 2002). Moreover, HRP II assay takes longer time $(72 \mathrm{~h})$ in culturing rather than other assays $(48 \mathrm{~h})$, which enables it an advantageous assay for testing of slow-acting drugs without incorporating any changes to the existing protocol (Noedl et al., 2002).

\section{HIGH THROUGHPUT SCREENING (HTS)}

Because of various limitations, such as the requirement of microscopist, data variation because of manual counting in the schizont maturation assay, use and disposal of radioactive substances in hypoxanthine assay, high cost, with several processing steps, along with less compatibility for HTS purpose, there was the development of assay in early 1990s based on flow cytometry analysis. The basic principle behind flow cytometry is that it takes advantage that human erythrocytes lack DNA so it stains and detects only parasite DNA. Briefly, the technology involves, incubation of parasites for a specified period with the test compounds, followed by fixation and then staining in which the whole parasitized cells can be stained with dye, hydroethidine or the nucleus of the parasite can be stained with DAPI, a fluorescent dye. Thereafter, flow cytometry can be used for counting treated and control cultures. Apart from this, flow cytometry also enables to differentiate between different stages of parasites inside erythrocyte with the help of gating. All these features make it a relatively simple assay, which gives high throughput and becomes the reason for replacement of older techniques, but the most important concern in using it, is its cost limitation. van Vianen et al. (1990), reported a fully automated analysis of drug tests by flow cytometry and they previously used flow cytometry for the screening of a newly developed drug. The flow cytometric method also determines schizont maturation but allows the exact number of nuclei per parasite to be determined, giving a more accurate account of the development in culture. Additionally, the parasitemia is counted in each well, so that a correction can be made for reinvasion.
A variety of different experiments, designed to study drug sensitivity, invasion-blocking, optimization of culture conditions, and the comparative relative fitness of parasite populations, can be analyzed without any alterations of the culture procedures. Flow cytometry is more accurate in counting parasitemia, for instance, and can differentiate between developmental stages, which improve the reading of tests compared with conventional techniques. This can result in an increase in the number of successful tests, but it can also lead to the simplification of culture procedures. An additional improvement is the automation of the analysis and processing of the data. All data are processed in a standardized way, maintaining objectivity, and the data remain available for re-examination. Data from large numbers of tests can be combined. The results are directly available in tables and graphs, which are especially important in large studies.

\section{FLUORESCENCE-BASED ASSAY}

Furthermore, the need for highly efficient throughput as well as the demand for non-radioactive assays resulted in the development of new fluorescence-based techniques which involves fast automatic quantification of parasite growth after staining parasites with fluorescent DNA binding dyes such as ethidium bromide (Waki et al., 1986). Binding of ethidium bromide to DNA causes the enhancement of its fluorescence intensity which is proportional to the amount of parasite DNA. This method was a replacement method to other radioactive assays in the late 1980s and was also applicable for screening antimalarials. Later a number of fluorescence dyes were used for HTS of drugs. Baniecki et al. (2007), revealed the compatibility and robustness for observing Plasmodium growth in HTS using DAPI, in a 384-well microtiter plate. Apart from this, few other DNA intercalating dyes, such as SYBR Green I, YOYO-1, and PicoGreen, have been recently described for measuring in vitro Plasmodium growth inhibition (Bennett et al., 2004; Smilkstein et al., 2004; Kosaisavee et al., 2006; Quashie et al., 2006; Weisman et al., 2006; Baniecki et al., 2007). As mature erythrocytes do not have RNA and DNA, the dye specifically binds to parasite DNA at the erythrocytic stage of $P$. falciparum and is significantly highly sensitive to well-defined spectral peaks, and is also less mutagenic when compared with ethidium bromide (Bennett et al., 2004). A study carried out by Smilkstein et al. (2004), demonstrated that the values of $\mathrm{IC}_{50}$ were the same with SYBR Green I as those obtained with the radioisotope, $\left[{ }^{3} \mathrm{H}\right]$ ethanolamine incorporation.

Recent advances in implication of transfection technology on malaria parasite enable the initiation of the transgenic type of parasite lines that express different reporters (Crabb, 2002), and it is found to be more sensitive like other standard radioactive incorporation assay with nearly zero background luminescence which does not require empty wells or uninfected erythrocytes as negative controls (Sanchez et al., 2007). Cui et al. (2008), generated stably expressing $P$. falciparum lines with a reporter firefly luciferase, which was optimized for 96-well microtiter plate format and serve as non-radiolabel-free, convenient system (Cui et al., 2007; Khan et al., 2012). Besides, the assay is simplified as 
it can use both unsynchronized and synchronized parasites with no significant differences, which suggest less time consumption and manpower. Moreover, most of the antimalarial assays take around $48-72 \mathrm{~h}$ to yield the results, however, luciferase assay takes only $12 \mathrm{~h}$ for interpreting the results and hence reliable for fast-acting drugs which suggest that expression of the reporter is altered before any parasite replicates. Although the assay is not fabricated for antimalarial resistance monitoring purposes, its simplicity indicates better feasibility of this luminescent assay for antimalarial HTS. Also, HTS requires at least 384-well microtiter culture plate and this assay can be performed in 384-well or even higher format as $Z^{\prime}$ scores of $>0.77$ supports for 384-well assay (Cui et al., 2008). The CyQUANT assay demonstrated by Sriwilaijaroen et al. (2004), is another fluorescence-based assay that uses CyQUANT GR cyanine dye that displays strong fluorescence, which can easily be detected at the excitation of $485 \mathrm{~nm}$ and visualized at $530 \mathrm{~nm}$ with a flow cytometer. The assay was found to be optimum for in vitro antimalarial assays and the GR dye shows optimum sensitivity and widest linearity range in comparison to other cyanine dyes (Sriwilaijaroen et al., 2004).

\section{IN VITRO BETA-HEMATIN FORMATION ASSAY}

Hemozoin is a non-toxic metabolite synthesized by the malaria parasite during heme metabolism that elucidates one of the distinct features of Plasmodium. Inhibition of heme metabolism leads to the acquisition of toxic heme that ultimately kills Plasmodium as a result of membrane lysis and hindrance in other metabolic functions in Plasmodium (Francis et al., 1997; Pandey et al., 1999; Stojiljkovic et al., 2001).

Briefly, for estimation of beta-hematin as a part of the antimalarial screening, the procedure involves beta-hematin formation which is initiated after addition of a catalytic factor in appropriate amount or nucleation. Thereafter, test compounds are added to the reaction mixtures followed by incubation for $12-24 \mathrm{~h}$ and finally the resulting beta-hematin is quantitated by different methods. (Tekwani and Walker, 2005). Most protocols involve differentiation of beta-hematin pellet through filtration or centrifugation followed by sequential washing of pellet with either water or solution of Tris-HCL/SDS and alkaline bicarbonate solution or DMSO. Besides, various experimental approaches are mentioned about beta-hematin estimation in vitro and use of this for evaluating antimalarial screening. Quantification of beta-hematin is the major step in this assay that can be done by a number of techniques such as spectrophotometric (Basilico et al., 1998; Pandey et al., 1999; Baelmans et al., 2000; Parapini et al., 2000; Tripathi et al., 2001, 2004; Deharo et al., 2002) radioisotopic (Kurosawa et al., 2000), fluorometric (Sullivan and Meshnick, 1996; Rebelo et al., 2013), and HPLC-based (Berger et al., 1995). Monomeric heme and hemozoin/beta-hematin may also be differentiated by FT-IR spectroscopy (Slater et al., 1991).

A rapid screening assay for antimalarial drugs has been developed from Plasmodium to determine deoxyhypusine and hypusine formed with the purified enzymes DHS and DOHH (Kaiser et al., 2012).

\section{IN VITRO ASSAYS TARGETING LIVER STAGES}

Gego et al. (2006) developed a new approach based on infrared fluorescence detection to automatically and rapidly quantify Plasmodium liver schizonts in vitro. Briefly, the technique involves plating of HepG2 or primary hepatocytes on plastic plates for about $24 \mathrm{~h}$ before inoculation of Plasmodium sporozoites, which follows short centrifugation, washing, and incubation of cells for $48 \mathrm{~h}$ for 5 days before quantification. Quantification was done through the Odyssey infrared imaging system combined with a colony counter, and this approach was validated against three strains of $P$. berghei (ANKA strain), P. yoelii (265BY strain), and P. falciparum (NF54 strain) (Gego et al., 2006).

\section{IN VITRO ASSAY FOR GAMETOCYTES}

Gametocytes of P. falciparum undergoes five morphologically separate indistinguishable stages within erythrocytes over a period of between 8 and 12 days (Baker, 2010) and then they retain in peripheral blood for few weeks (Bousema et al., 2010). Gametocyte stage represents "druggable" transmission-related stage of Plasmodium and therefore there are so many in vitro methods that have been studied and published for assessing the gametocidal activity of compounds (Lucantoni and Avery, 2012). Most of these assays are based on metabolic activity measurement (Peatey et al., 2011), which is directly correlated with the intensity of fluorescence dye emitted from transgenic parasite lines that express a kind of reporter gene (Buchholz et al., 2011), alamar Blue, an oxidoreduction indicator (Tanaka and Williamson, 2011), and bioluminescence-mediated detection of ATP (Lelièvre et al., 2012) and also, pLDH activity is studied recently (Roncales et al., 2012). Later, Tanaka et al. (2013) modified and validated alamar Blue indicator assay suited for HTS and to assess the viability, gametocytes are also added to this concept. All the above methods mainly focused on gametocytogenesis at later steps of development, as immature stages are often hypothesized for their sensitivity to most of the antimalarial drugs and, therefore, are of limited concern. Till now, there is no such study that produces an extensive assessment on the level of sensitivity at early-stage gametocytes with respect to most of the antimalarials, although there are few studies which are limited to few established drugs (Smalley, 1977; Chutmongkonkul et al., 1992; Fleck et al., 1996; Chavalitshewinkoon-Petmitr et al., 2000; Adjalley et al., 2011; Buchholz et al., 2011). Besides, previous and some recent reports illustrate the differences that exist with respect to the development of a different chemosensitivity pattern of immature developing gametocytes as well as asexual stages to several antimalarial compounds such as chloroquine (Chutmongkonkul et al., 1992), pyrimethamine (Chutmongkonkul et al., 1992) atovaquone (Smalley, 1977; Fleck et al., 1996; Adjalley et al., 
2011), and methylene blue (Buchholz et al., 2011). D'Alessandro et al. (2013) reported the fabrication of novel, quick and cheapest assay for screening gametocidal compounds by measuring the activity of pLDH of gametocytes in 96-well plates. The assay validation was carried out using reference anti-gametocyte drugs, and the result was interpreted by comparing the readout measures of mosquito infectivity using the standard membrane feeding assay (SMFA), which is the current gold standard transmission blocking assay (van der Kolk et al., 2005; Stone et al., 2014). Recently, an HTS assay applying luciferase approach has been performed in assessing compound activity on early (stages I-III) P. falciparum. The authors demonstrated the application of this assay with reference antimalarials and also reported few new leads from the MMV Malaria Box (Lucantoni et al., 2013). Lucantoni et al. (2016) extended their previous application to provide a prompt, straightforward, and cost-effective HTS assay, which is capable of assessing compound activity against late-stage gametocytes (stages IV and V), with the additional benefit of profiling activity throughout the process of gametocyte development and maturation. The assay is also suitable for evaluating compound activity at an incubation period of up to $72 \mathrm{~h}$, which illustrates its excellent quality and reproducibility, having average $Z^{\prime}$-values of $0.85 \pm 0.01$ (Lucantoni et al., 2016).

At present, new drugs that hinder both or either hepatocyte or gametocyte development, are needed to block parasite transmission. Thus, screening methods that are suitable for exploring new gametocidal compounds are needed for securing further transmission of malaria mostly in the endemic regions. However, a major drawback in the development of these assays is the unavailability of standardized protocols for gametocyte cultivation. However, there are few reference compounds against gametocyte development that mostly used for validation of new assays.

\section{NEXT-GENERATION ADVANCES ASSAY}

In recent years, breakthroughs in the field of stem-cell research provide an additional opportunity for studying new prospectives in parasite biology, especially those concerned with the stages of the parasite cell cycle that seem to be challenging so far or even impossible task may seek through this new advances at in vitro level (Figure 3).

\section{HEPATIC STAGE MALARIA: ROLE OF INDUCED PLURIPOTENT CELLS}

For the modeling of the hepatic stage of malaria, hepatocyte cell lines that is, HepG2, HCO4, are the commonly used ones, and the most commonly used malaria species are Plasmodium sporozoites $P$. yoelii, P. berghei, P. falciparum, and $P$. vivax (March et al., 2013). But metabolism in immortal cell lines is a little bit different than in vivo ones and thus they may not mimic in vivo conditions properly (Noulin, 2016). Again primary hepatocytes are the natural hosts of malaria (March et al., 2013). Primary rodent hepatocyte culture came into the scenario to solve this problem and $P$. vivax was successfully cultured in this model (Mazier et al., 1984). The use of human hepatocyte for the culture of malaria parasite was established by Dembélé et al. (2014). They successfully cultured exoerythrocytic (EE) stages of $P$. falciparum and $P$. cynomolgi in vitro and were also able to develop hypnozoite form. This protocol may be very useful for the search of drugs that kill hypnozoites and also to study hypnozoite biology (Dembélé et al., 2014). But the use of primary hepatocyte brings another problem; that is, it needs continuous availability of fresh cells. The procedure for cryopreservation was established by March et al. (2013), and the use of this protocol permitted reuse of cryopreserved primary hepatocytes and these reused cultures showed evidence of Plasmodium invasion (March et al., 2013).

However, the primary hepatocytes are derived from a small pool of donors. So this small number of sample pool may not be representative of the genetic diversity seen in human populations (Noulin, 2016). Hepatocytes derived from stem cells, overcome many of these limitations. Stem-cell-derived hepatocytes may represent more diverse genotypes; renewable and personalization can be done with the expression of rare genotypes ( $\mathrm{Ng}$ et al., 2015).

Induced pluripotent stem cells (iPSCs) can be differentiated in vitro to produce iHLCs with many intermediate stages (pluripotent, definitive endoderm, specified hepatic, immature hepatocyte, mature hepatocyte) using the specific cell culture protocol as mentioned by Si-Tayeb et al. (2010). These stem cells can be collected from a huge pool of donors and this can give us a bank of iPSCs with huge genetic diversity ( $\mathrm{Ng}$ et al., 2015). Ng et al. (2015) also tested whether iPSC-derived iHLCs can be used as a model for the hepatic stage of malaria or not. In their experiment, iHLCs, demonstrated typical hepatocyte morphology with a polygonal shape and expressed prototypical hepatocyte markers such as human albumin, $\alpha 1$-anti-trypsin, and $\alpha$-fetoprotein. iHLCs were positive for both CD81 and SRB1, which are host entry factors for liver-stage malaria, and they were appropriately localized to the cell surface. In their experiment they found that the liver stage of Plasmodium can be effectively modeled using iPSC derived iHLCs. But it was found that iHLCs infected with Plasmodium were sensitive to atovaquone, but not to primaquine. Atovaquone is active against Plasmodium in the parent form, but primaquine requires bioactivation by the action of hepatic enzymes. In the next step of their experiment, they used small molecule (FPH1) to upregulate adult human drug metabolizing enzyme. In FPH1 treated, Plasmodium infected iHLCs, primaquine was effective against both $P$. yoelii and $P$. falciparum EEFs, ( $\mathrm{Ng}$ et al., 2015). Therefore, this model can be an important part of antimalarial drug discovery with specifically targeting at the liver stage.

\section{ERYTHROCYTIC PHASE}

Giarratana et al. (2011) demonstrated a novel technique of generating erythrocytes in vitro from CD34+ HSCs. These 


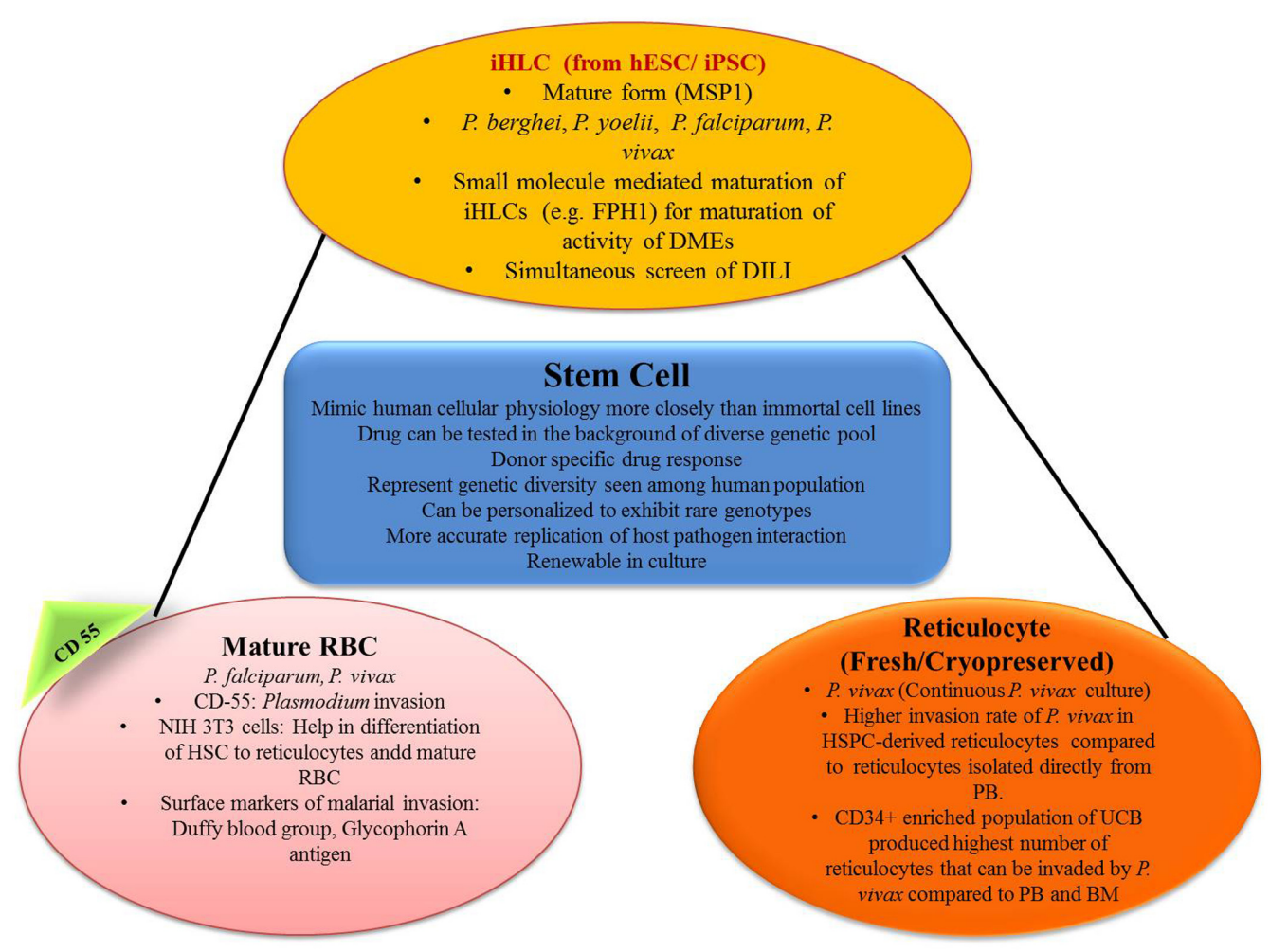

FIGURE 3 | Role of stem cell in generating in vitro efficacy models for malaria. iHLC, induced human hepatocyte-like cells; hESC, human embryonic stem cells; MSP1, merozoite surface protein 1; FPH1, functional proliferation of primary hepatocytes 1; DMEs, drug metabolizing enzymes; DILI, drug-induced liver injury; CD55, clusters of differentiation; NIH 3T3, mouse embryonic fibroblast cell line; HSC, hematopoietic stem cells; HSPC, hematopoietic stem/progenitor cell; PB, peripheral blood; UCB, umbilical cord blood; BM, bone marrow.

erythrocytes were similar in terms of deformability, enzyme content, the capacity of their hemoglobin to fix/release oxygen, and expression of blood group antigens to normal endogenous erythrocytes. In a phase 1 study of the same, it was successfully translated into humans with a similar half-life (Giarratana et al., 2011). Fernandez-Becerra et al. (2013) showed that those erythrocytes which are acquired from either peripheral blood or bone marrow CD34+ human HSCs (hHSCs) are mostly permissive for Plasmodium infection. In their experiment, on day 14 growing erythrocytes showed expression of glycophorin A along with Duffy blood group antigen, which is considered as a surface marker for the invasion of Plasmodium. After that invasion assays were performed using 3D7 $P$. falciparum parasite strain and $P$. vivax isolates and it was demonstrated that erythrocytes and reticulocytes both differentiated from CD34+ hHSCs and were acquiescent for the invasion of both Plasmodium species (Fernandez-Becerra et al., 2013).

Plasmodium falciparum can invade erythrocytes of all stages, but $P$. vivax preferably invades reticulocytes (Golenda et al., 1997). But reticulocytes are only $0.5-1 \%$ of the total erythrocytes in the bloodstream and again their lifespan before maturation is only $24 \mathrm{~h}$. Earlier methods used to concentrate reticulocytes were centrifugation (Golenda et al., 1997; Borlon et al., 2012), and use of lysis buffer (Grimberg et al., 2012). Recent studies clearly demonstrated the preference of $P$. vivax toward reticulocytes with high CD71 positive cells (maturation of reticulocytes is associated with selective removal of membrane proteins, e.g., transferrin receptor, CD71) (Martín-Jaular et al., 2013). This shows the possibility of HSC-derived reticulocytes in the drug discovery process against P. vivax. Panichakul et al. (2007) developed an in vitro method in which human cord HSCs were differentiated artificially in the presence of erythropoietin to produce susceptible erythrocyte precursors. Duffy positive reticulocytes appeared after 10 days and the maximum numbers were found in 14-16 days of culture. $P$. vivax was co-cultured on day 10 onward and parasitic growth was detected in growing erythrocytes. These cultures were maintained for $>2$ weeks to 85 days by supplying erythrocytes. Peak reticulocyte count (0.5\%) was observed on day 14 and parasitemia was very less between 0.0001 and $0.0013 \%$ (Panichakul et al., 2007). Noulin et al. (2012) developed a method in which reticulocyte first appeared at day 12 of differentiation and the peak reticulocyte count was observed on day 14 (5\% on day 13 and $18 \%$ on day 14 ). The reticulocyte count then decreased suddenly to $10 \%$ on day 16 which almost disappeared on day 19 (Noulin et al., 2012). Another problem was fresh reticulocytes were to be used along with fresh vivax isolates. Noulin et al. (2012) developed a modified technique of cryopreservation of HSC derived reticulocytes which can later be used for invasive tests which is an important step toward continuous $P$. vivax culture (Noulin et al., 2012). 


\section{CONCLUSION}

At the compound screening stage, many thousands of compounds are screened (1,000-2,000,000 compounds per screening campaign) using recent HTS techniques. Now, after identification of hits, which has an average of approximately $1.0 \%$, they are supposed to be ranked which is based on several criteria (such as the way of synthesis, potency, toxicity; contradiction and other limitations and novelty to use) for finding out the most optimum leads. Most of the compounds are validated and tested in low throughput screening methods which include radical cure and transmission assays. However, both these are very expensive along with time-consumption and thus, they are mostly applied to the selective size of compounds. After leads selection, optimization for optimum characteristics such as maximum efficiency along with better bioavailability and less toxicity is taken into consideration. Finally, modified leads undergo further evaluation, and later those with maximum favorable risk-benefit ratio are forwarded to the next step of development; that is, preclinical evaluation and in case the lead is found successful, and then it may be carried into further clinical development phases.

Out of several in vitro/ex vivo susceptibility assays, the most demanding antimalarial assays includes, HRP-II ELISA, radioisotopic incorporation, and presently the SYBR Green I method and all are subjected to lots of data variabilities. The reason for these variabilities and confounding interpretations is the differences in protocol of assay methods, different laboratory conditions, use of distinct parasite strain for susceptibility phenotypes, and other differences arising because of individual technical performance (Noedl et al., 2003b; Bacon et al., 2007; Akala et al., 2011). Apart from the above conditions, drug properties, such as its solubility, $\mathrm{pH}$ difference, and mechanism of action display, method-dependent positive or negative effects on data analysis along with result interpretation (Wein et al., 2010). Also, it is challenging to extrapolate the results of in vitro testing to in vivo that is, intact systems biology (Rothman, 2002; De Clercq, 2005). Hence, more careful observation is required regarding to proper lead selection and optimization and in vitro toxicity profile. Again, in a drug requiring metabolic activation, in vitro evaluation techniques may be little difficult, although primary hepatocyte culture and other newer techniques such as the application of stem cells

\section{REFERENCES}

Adjalley, S. H., Johnston, G. L., Li, T., Eastman, R. T., Ekland, E. H., Eappen, A. G., et al. (2011). Quantitative, assessment of Plasmodium falciparum sexual development reveals potent transmission-blocking activity by methylene blue. Proc. Natl. Acad. Sci. U.S.A. 108, E1214-E1223. doi: 10.1073/pnas.1112037108

Akala, H. M., Eyase, F. L., Cheruiyot, A. C., Omondi, A. A., Ogutu, B. R., Waters, N. C., et al. (2011). Antimalarial drug sensitivity profile of western Kenya Plasmodium falciparum field isolates determined by a SYBR Green I in vitro assay and molecular analysis. Am. J. Trop. Med. Hyg. 85, 34-41. doi: 10.4269/ ajtmh.2011.10-0674

Bacon, D. J., Jambou, R., Fandeur, T., Le Bras, J., Wongsrichanalai, C., Fukuda, M. M., et al. (2007). World antimalarial resistance network (WARN) II: in vitro antimalarial drug susceptibility. Malar. J. 6:120. doi: 10.1186/1475-2875-6-120 give insight on how to solve this problem (Li and Kedderis, 1997; Gómez-Lechón et al., 2003). Mathematical models and newer techniques such as "human on chip" may be helpful for better in vitro-in vivo correlation (Sung et al., 2010; Quignot and Bois, 2013). Apart from this, PB-PK models are important components to these extrapolations (Yoon et al., 2012).

However, in vitro tissue and organ sensitivity may be completely different to that what observed in cultured cells in vitro and thus in vitro cellular PK-PD profile may be different from in vivo cellular PK-PD profile. Therefore, PB-PK models are important components to these extrapolations (Yoon et al., 2012).

Irrespective of these deficiencies/disadvantages, in vitro techniques are cornerstones of the new drug discovery process. They provide us direct knowledge in relation to a potential new drug/disease setting; multiple compounds with different modes of action can be tested and, depending on the throughput of the assay, over a full concentration-effect range; it allows for some serendipity, as well as hypothesis-free, analysis of compounds which provides strong data-driven possibilities for subsequent assessment in highly complex phenotypic or in vivo systems. Some of the advantages that are offered by the in vitro efficacy models include the following:

- Simple

- Even human cells can be used for evaluation, so we can gather human data

- Convenience: large number of compounds can be evaluated at the same time

- Automation: as in case of HTS

- Precise and efficient

- Rapid

- Synergism or antagonism with drug combinations can be studied

- Better assessment of the intrinsic activity of a drug.

\section{AUTHOR CONTRIBUTIONS}

BM, RS, PS, and SS designed the layout of review. SS and PS collected the data. BM and RS analyzed the data. SS, PS, RS, and $\mathrm{BM}$ prepared the article.

Baelmans, R., Deharo, E., Muñoz, V., Sauvain, M., and Ginsburg, H. (2000). Experimental conditions for testing the inhibitory activity of chloroquine on the formation of beta-hematin. Exp. Parasitol. 96, 243-248. doi: 10.1006/expr. 2000.4558

Baker, D. A. (2010). Malaria gametocytogenesis. Mol. Biochem. Parasitol. 172, 57-65. doi: 10.1016/j.molbiopara.2010.03.019

Baniecki, M. L., Wirth, D. F., and Clardy, J. (2007). High-throughput Plasmodium falciparum growth assay for malaria drug discovery. Antimicrob. Agents Chemother. 51, 716-723. doi: 10.1128/AAC.01144-06

Basco, L. K. (2007). Field Application of in vitro Assays for the Sensitivity of Human Malaria Parasites to Antimalarial Drugs. Geneva: World Health Organization.

Basco, L. K., Marquet, F., Makler, M. M., and Le Bras, J. (1995). Plasmodium falciparum and Plasmodium vivax: lactate dehydrogenase activity and its 
application for drug susceptibility assay. Exp. Parasitol. 80, 260-271. doi: 10. 1006/expr.1995.1032

Basilico, N., Pagani, E., Monti, D., Olliaro, P., and Taramelli, D. (1998). A microtitre-based method for measuring the haem polymerization inhibitory activity (HPIA) of antimalarial drugs. J. Antimicrob. Chemother. 42, 55-60. doi: $10.1093 / \mathrm{jac} / 42.1 .55$

Bennett, T. N., Paguio, M., Gligorijevic, B., Seudieu, C., Kosar, A. D., Davidson, E., et al. (2004). Novel, rapid, and inexpensive cell-based quantification of antimalarial drug efficacy. Antimicrob. Agents Chemother. 48, 1807-1810. doi: 10.1128/AAC.48.5.1807-1810.2004

Berger, B. J., Bendrat, K., and Cerami, A. (1995). High-performance liquid chromatographic analysis of biological and chemical heme polymerization. Anal. Biochem. 231, 151-156. doi: 10.1006/abio.1995.1514

Bergmann-Leitner, E. S., Mease, R. M., Duncan, E. H., Khan, F., Waitumbi, J., and Angov, E. (2008). Evaluation of immunoglobulin purification methods and their impact on quality and yield of antigen-specific antibodies. Mal. J. 7:129. doi: 10.1186/1475-2875-7-129

Borlon, C., Russell, B., Sriprawat, K., Suwanarusk, R., Erhart, A., Renia, L., et al. (2012). Cryopreserved Plasmodium vivax and cord blood reticulocytes can be used for invasion and short term culture. Int. J. Parasitol. 42, 155-160. doi: 10.1016/j.ijpara.2011.10.011

Bousema, T., Okell, L., Shekalaghe, S., Griffin, J. T., Omar, S., Sawa, P., et al. (2010). Revisiting the circulation time of Plasmodium falciparum gametocytes: molecular detection methods to estimate the duration of gametocyte carriage and the effect of gametocytocidal drugs. Malar. J. 9:136. doi: 10.1186/14752875-9-136

Brasseur, P., Agnamey, P., Moreno, A., and Druilhe, P. (2001). Evaluation of in vitro drug sensitivity of antimalarials for Plasmodium falciparum using a colorimetric assay (DELI-microtest). Med. Trop. (Mars) 61, 545-547.

Brown, W. M., Yowell, C. A., Hoard, A., Vander Jagt, T. A., Hunsaker, L. A., Deck, L. M., et al. (2004). Comparative structural analysis and kinetic properties of lactate dehydrogenases from the four species of human malarial parasites. Biochemistry 43, 6219-6229. doi: 10.1021/bi049892w

Buchholz, K., Burke, T. A., Williamson, K. C., Wiegand, R. C., Wirth, D. F., and Marti, M. (2011). A high-throughput screen targeting malaria transmission stages opens new avenues for drug development. J. Infect. Dis. 203, 1445-1453. doi: 10.1093/infdis/jir037

Chavalitshewinkoon-Petmitr, P., Pongvilairat, G., Auparakkitanon, S., and Wilairat, P. (2000). Gametocytocidal activity of pyronaridine and DNA topoisomerase II inhibitors against multidrug-resistant Plasmodium falciparum in vitro. Parasitol. Int. 48, 275-280. doi: 10.1016/S1383-5769(99) 00028-8

Chulay, J. D., Haynes, J. D., and Diggs, C. L. (1983). Plasmodium falciparum: assessment of in vitro growth by $[3 \mathrm{H}]$ hypoxanthine incorporation. Exp. Parasitol. 55, 138-146. doi: 10.1016/0014-4894(83)90007-3

Chutmongkonkul, M., Maier, W. A., and Seitz, H. M. (1992). A new model for testing gametocytocidal effects of some antimalarial drugs on Plasmodium falciparum in vitro. Ann. Trop. Med. Parasitol. 86, 207-215. doi: 10.1080/ 00034983.1992 .11812656

Crabb, B. S. (2002). Transfection technology and the study of drug resistance in the malaria parasite Plasmodium falciparum. Drug Resist. Updat. 5, 126-130. doi: $10.1016 / S 1368-7646(02) 00085-7$

Cui, L., Miao, J., and Cui, L. (2007). Cytotoxic effect of curcumin on malaria parasite Plasmodium falciparum: inhibition of histone acetylation and generation of reactive oxygen species. Antimicrob. Agents Chemother. 51, 488494. doi: 10.1128/AAC.01238-06

Cui, L., Miao, J., Wang, J., Li, Q., and Cui, L. (2008). Plasmodium falciparum: development of a transgenic line for screening antimalarials using firefly luciferase as the reporter. Exp. Parasitol. 120, 80-87. doi: 10.1016/j.exppara. 2008.05.003

D'Alessandro, S., Silvestrini, F., Dechering, K., Corbett, Y., Parapini, S., Timmerman, M., et al. (2013). A Plasmodium falciparum screening assay for anti-gametocyte drugs based on parasite lactate dehydrogenase detection. $J$. Antimicrob. Chemother. 68, 2048-2058. doi: 10.1093/jac/dkt165

De Clercq, E. (2005). Recent highlights in the development of new antiviral drugs. Curr. Opin. Microbiol. 8, 552-560. doi: 10.1016/j.mib.2005.08.010

Deharo, E., García, R. N., Oporto, P., Gimenez, A., Sauvain, M., Jullian, V., et al. (2002). A non-radiolabelled ferriprotoporphyrin IX biomineralisation inhibition test for the high throughput screening of antimalarial compounds. Exp. Parasitol. 100, 252-256. doi: 10.1016/S0014-4894(02)00027-9

Dembélé, L., Franetich, J. F., Lorthiois, A., Gego, A., Zeeman, A. M., Kocken, C. H., et al. (2014). Persistence and activation of malaria hypnozoites in long-term primary hepatocyte cultures. Nat. Med. 20, 307-312. doi: 10.1038/nm.3461

Desakorn, V., Silamut, K., Angus, B., Sahassananda, D., Chotivanich, K., Suntharasamai, P., et al. (1997). Semi-quantitative measurement of Plasmodium falciparum antigen PfHRP2 in blood and plasma. Trans. R. Soc. Trop. Med. Hyg. 91, 479-483. doi: 10.1016/S0035-9203(97)90292-3

Desjardins, R. E., Canfield, C. J., Haynes, J. D., and Chulay, J. D. (1979). Quantitative assessment of antimalarial activity in vitro by a semiautomated microdilution technique. Antimicrob. Agents Chemother. 16, 710-718. doi: 10. 1128/AAC.16.6.710

Dondorp, A. M., Nosten, F., Yi, P., Das, D., Phyo, A. P., Tarning, J., et al. (2009). Artemisinin resistance in Plasmodium falciparum malaria. N. Engl. J. Med. 361, 455-467. doi: 10.1056/NEJMoa0808859

Druilhe, P., Moreno, A., Blanc, C., Brasseur, P. H., and Jacquier, P. (2001). A colorimetric in vitro drug sensitivity assay for Plasmodium falciparum based on a highly sensitive double-site lactate dehydrogenase antigen-capture enzymelinked immunosorbent assay. Am. J. Trop. Med. Hyg. 64, 233-241.

Elabbadi, N., Ancelin, M. L., and Vial, H. J. (1992). Use of radioactive ethanolamine incorporation into phospholipids to assess in vitro antimalarial activity by the semiautomated microdilution technique. Antimicrob. Agents Chemother. 36, 50-55. doi: 10.1128/AAC.36.1.50

Fernandez-Becerra, C., Lelievre, J., Ferrer, M., Anton, N., Thomson, R., and Peligero, C. (2013). Red blood cells derived from peripheral blood and bone marrow CD34? human haematopoietic stem cells are permissive to Plasmodium parasites infection. Mem. Inst. Oswaldo Cruz 108, 801-803. doi: 10.1590/00740276108062013019

Fidock, D. A., Rosenthal, P. J., Croft, S. L., Brun, R., and Nwaka, S. (2004), Antimalarial drug discovery: efficacy models for compound screening. Nat. Rev. Drug Discov. 3, 509-520. doi: 10.1038/nrd1416

Fleck, S. L., Pudney, M., and Sinden, R. E. (1996). The effect of atovaquone (566C 80 ) on the maturation and viability of Plasmodium falciparum gametocytes in vitro. Trans. R. Soc. Trop. Med. Hyg. 90, 309-312. doi: 10.1016/ S0035-9203(96)90266-7

Francis, S. E., Sullivan, D. J. Jr., and Goldberg, D. E. (1997). Hemoglobin metabolism in the malaria parasite Plasmodium falciparum. Annu. Rev. Microbiol. 51, 97-123. doi: 10.1146/annurev.micro.51.1.97

Geary, T. G., Divo, A. A., and Jensen, J. B. (1983). An in vitro assay system for the identification of potential antimalarial drugs. J. Parasitol. 69, 577-583. doi: $10.2307 / 3281373$

Gego, A., Silvie, O., Franetich, J. F., Farhati, K., Hannoun, L., Luty, A. J., et al. (2006). New approach for high-throughput screening of drug activity on Plasmodium liver stages. Antimicrob. Agents Chemother. 50, 1586-1590. doi: 10.1128/AAC.50.4.1586-1589.2006

Gelb, M. H. (2007). Drug discovery for malaria: a very challenging and timely endeavor. Curr. Opin. Chem. Biol. 11, 440-445. doi: 10.1016/j.cbpa.2007.05.038

Giarratana, M. C., Rouard, H., Dumont, A., Kiger, L., Safeukui, I., Le Pennec, P. Y., et al. (2011). Proof of principle for transfusion of in vitro-generated red blood cells. Blood 118, 5071-5079. doi: 10.1182/blood-2011-06-362038

Golenda, C. F., Li, J., and Rosenberg, R. (1997). Continuous in vitro propagation of the malaria parasite Plasmodium vivax. Proc. Natl. Acad. Sci. U.S.A. 94, 6786-6791. doi: 10.1073/pnas.94.13.6786

Gómez-Lechón, M. J., Donato, M. T., Castell, J. V., and Jover, R. (2003). Human hepatocytes as a tool for studying toxicity and drug metabolism. Curr. Drug Metab. 4, 292-312. doi: 10.2174/1389200033489424

Grimberg, B. T., Scheetz, E. A., Erickson, J. J., Bales, J. M., David, M., DaumWoods, K., et al. (2012). Increased reticulocyte count from cord blood samples using hypotonic lysis. Exp. Parasitol. 132, 304-307. doi: 10.1016/j.exppara.2012. 07.006

Hernandez, L., Kodali, S., Cully, D., Singh, S., and Wang, J. (2006). A targetspecific whole cell assay for antibacterial drug discovery. Protoc. Exch. doi: 10.1038/nprot.2006.130

Hobbs, C., and Duffy, P. (2011). Drugs for malaria: something old, something new, something borrowed. F1000 Biol. Rep. 3:24. doi: 10.3410/B3-24

Howard, R. J., Uni, S., Aikawa, M., Aley, S. B., Leech, J. H., Lew, A. M., et al. (1986). Secretion of a malarial histidine-rich protein (PfHRPII) from Plasmodium 
falciparum-infected erythrocytes. J. Cell Biol. 103, 1269-1277. doi: 10.1083/jcb. 103.4.1269

Hughes, J. P., Rees, S., Kalindjian, S. B., and Philpott, K. L. (2011). Principles of early drug discovery. Br. J. Pharmacol. 162, 1239-1249. doi: 10.1111/j.14765381.2010.01127.x

Hyde, J. E. (2007). Drug-resistant malaria - an insight. FEBS J. 274, 4688-4698. doi: 10.1111/j.1742-4658.2007.05999.x

Kaiser, A., Khomutov, A., Simonian, A., and Agostinelli, E. A. (2012). A rapid and robust assay for the determination of the amino acid hypusine as a possible biomarker for a high-throughput screening of antimalarials and for the diagnosis and therapy of different diseases. Amino Acids 42, 1651-1659. doi: $10.1007 / \mathrm{s} 0072601108595$

Khan, T., van Brummelen, A. C., Parkinson, C. J., and Hoppe, H. C. (2012), ATP and luciferase assays to determine the rate of drug action in in vitro cultures of Plasmodium falciparum. Malar. J. 11, 369. doi: 10.1186/1475-2875$11-369$

Kosaisavee, V., Suwanarusk, R., Nosten, F., Kyle, D. E., Barrends, M., Jones, J., et al. (2006). Plasmodium vivax: isotopic, PicoGreen, and microscopic assays for measuring chloroquine sensitivity in fresh and cryopreserved isolates. Exp. Parasitol. 114, 34-39. doi: 10.1016/j.exppara.2006.02.006

Kurosawa, Y., Dorn, A., Kitsuji-Shirane, M., Shimada, H., Satoh, T., Matile, H., et al. (2000). Hematin polymerization assay as a high-throughput screen for identification of new antimalarial pharmacophores. Antimicrob. Agents Chemother. 44, 2638-2644. doi: 10.1128/AAC.44.10.2638-2644. 2000

Lelièvre, J., Almela, M. J., Lozano, S., Miguel, C., Franco, V., Leroy, D., et al. (2012). Activity of clinically relevant antimalarial drugs on Plasmodium falciparum mature gametocytes in an ATP bioluminescence "transmission blocking" assay. PLOS ONE 7:e35019. doi: 10.1371/journal.pone.0035019

Li, A. P., and Kedderis, G. L. (1997). Primary hepatocyte culture as an experimental model for the evaluation of interactions between xenobiotics and drugmetabolizing enzymes. Chem. Biol. Interact. 107, 1-3. doi: 10.1016/S00092797(97)00069-0

Liberati, A., Altman, D. G., Tetzlaff, J., Mulrow, C., Gøtzsche, P. C., Ioannidis, J. P., et al. (2009). The PRISMA statement for reporting systematic reviews and meta-analyses of studies that evaluate healthcare interventions: explanation and elaboration. BMJ 339:b2700. doi: 10.1136/bmj.b2700

Lucantoni, L., and Avery, V. M. (2012). Whole-cell in vitro screening for gametocytocidal compounds. Future Med. Chem. 4, 2337-2360. doi: 10.4155/ fmc. 12.188

Lucantoni, L., Duffy, S., Adjalley, S. H., Fidock, D. A., and Avery, V. M. (2013). Identification of MMV malaria box inhibitors of Plasmodium falciparum earlystage gametocytes using a luciferase-based high-throughput assay. Antimicrob. Agents Chemother. 57, 6050-6062. doi: 10.1128/AAC.00870-13

Lucantoni, L., Fidock, D. A., and Avery, V. M. (2016). Luciferase-based, high-throughput assay for screening and profiling transmission-blocking compounds against Plasmodium falciparum gametocytes. Antimicrob. Agents Chemother. 60, 2097-2107. doi: 10.1128/AAC.01949-15

Lucantoni, L., Loganathan, S., and Avery, V. M. (2017). The need to compare: assessing the level of agreement of three high-throughput assays against Plasmodium falciparum mature gametocytes. Sci. Rep. 7:45992. doi: 10.1038/ srep45992

Makler, M. T., and Hinrichs, D. J. (1993). Measurement of the lactate dehydrogenase activity of Plasmodium falciparum as an assessment of parasitemia. Am. J. Trop. Med. Hyg. 48, 205-210. doi: 10.4269/ajtmh.1993. 48.205

Makler, M. T., Ries, J. M., Williams, J. A., Bancroft, J. E., Piper, R. C., Gibbins, B. L., et al. (1993). Parasite lactate dehydrogenase as an assay for drug sensitivity. Am. J. Trop. Med. Hyg. 48, 739-741. doi: 10.4269/ajtmh.1993.48.739

March, S., Ng, S., Velmurugan, S., Galstian, A., Shan, J., Logan, D. J., et al. (2013). A microscale human liver platform that supports the hepatic stages of Plasmodium falciparum and vivax. Cell Host Microbe 14, 104-115. doi: 10.1016/ j.chom.2013.06.005

Martín-Jaular, L., Elizalde-Torrent, A., Thomson-Luque, R., Ferrer, M., Segovia, J. C., Herreros-Aviles, E., et al. (2013). Reticulocyte-prone malaria parasites predominantly invade CD71hi immature cells: implications for the development of an in vitro culture for Plasmodium vivax. Malar. J. 12:434. doi: $10.1186 / 1475-2875-12-434$
Mazier, D., Landau, I., Druilhe, P., Miltgen, F., Guguen-Guillouzo, C., Baccam, D., et al. (1984). Cultivation of the liver forms of Plasmodium vivax in human hepatocytes. Nature 307, 367-369. doi: 10.1038/307367a0

Ndiaye, D., Patel, V., Demas, A., LeRoux, M., Ndir, O., Mboup, S., et al. (2010). A non-radioactive DAPI-based high-throughput in vitro assay to assess Plasmodium falciparum responsiveness to antimalarials-increased sensitivity of P. falciparum to chloroquine in Senegal. Am. J. Trop. Med. Hyg. 82, 228-230. doi: 10.4269/ajtmh.2010.09-0470

Ng, S., Schwartz, R. E., March, S., Galstian, A., Gural, N., Shan, J., et al. (2015). Human iPSC-derived hepatocyte-like cells support Plasmodium liver-stage infection in vitro. Stem Cell Rep. 4, 348-359. doi: 10.1016/j.stemcr.2015.01.002

Noedl, H., Faiz, M. A., Yunus, E. B., Rahman, M. R., Hossain, M. A., Samad, R., et al. (2003a). Drug-resistant malaria in Bangladesh: an in vitro assessment. Am. J. Trop. Med. Hyg. 68, 140-142.

Noedl, H., Se, Y., Schaecher, K., Smith, B. L., Socheat, D., and Fukuda, M. M. (2008). Evidence of artemisinin-resistant malaria in western Cambodia. N. Engl. J. Med. 359, 2619-2620. doi: 10.1056/NEJMc0805011

Noedl, H., Wernsdorfer, W. H., Miller, R. S., and Wongsrichanalai, C. (2002). Histidine rich protein II, a novel approach to antimalarial drug susceptibility testing. Antimicrob. Agents Chemother. 46, 1658-1664. doi: 10.1128/AAC.46.6. 1658-1664.2002

Noedl, H., Wongsrichanalai, C., and Wernsdorfer, W. H. (2003b). Malaria drugsensitivity testing: new assays, new perspectives. Trends Parasitol. 19, 175-181.

Nogueira, F. (2010). Methods for assessment of antimalarial activity in the different phases of the Plasmodium life cycle. Rev. Pan Amaz. Saude 1, 109-124. doi: 10.5123/S2176-62232010000300015

Noulin, F. (2016). Malaria modeling: in vitro stem cells vs in vivo models. World J. Stem Cells 8, 88-100. doi: 10.4252/wjsc.v8.i3.88

Noulin, F., Borlon, C., van den Eede, P., Boel, L., Verfaillie, C. M., D’Alessandro, U. et al. (2012). Cryopreserved reticulocytes derived from hematopoietic stem cells can be invaded by cryopreserved Plasmodium vivax isolates. PLOS ONE 7:e40798. doi: 10.1371/journal.pone.0040798

Pandey, A. V., Tekwani, B. L., Singh, R. L., and Chauhan, V. S. (1999). Artemisinin, an endoperoxide antimalarial, disrupts the hemoglobin catabolism and heme detoxification systems in malarial parasite. J. Biol. Chem. 274, 19383-19388. doi: $10.1074 /$ jbc.274.27.19383

Panichakul, T., Sattabongkot, J., Chotivanich, K., Sirichaisinthop, J., Cui, L., and Udomsangpetch, R. (2007). Production of erythropoietic cells in vitro for continuous culture of Plasmodium vivax. Int. J. Parasitol. 37, 1551-1557. doi: 10.1016/j.ijpara.2007.05.009

Parapini, S., Basilico, N., Pasini, E., Egan, T. J., Olliaro, P., Taramelli, D., et al. (2000). Standardization of the physicochemical parameters to assess in vitro the beta-hematin inhibitory activity of antimalarial drugs. Exp. Parasitol. 96, 249-256. doi: 10.1006/expr.2000.4583

Peatey, C. L., Spicer, T. P., Hodder, P. S., Trenholme, K. R., and Gardiner, D. L. (2011). A high-throughput assay for the identification of drugs against late-stage Plasmodium falciparum gametocytes. Mol. Biochem. Parasitol. 180, 127-131. doi: 10.1016/j.molbiopara.2011.09.002

Phyo, A. P., Nkhoma, S., Stepniewska, K., Ashley, E. A., Nair, S., McGready, R., et al. (2012). Emergence of artemisinin-resistant malaria on the western border of Thailand: a longitudinal study. Lancet 379, 1960-1966. doi: 10.1016/S01406736(12)60484-X

Quashie, N. B., de Koning, H. P., and Ranford-Cartwright, L. C. (2006). An improved and highly sensitive microfluorimetric method for assessing susceptibility of Plasmodium falciparum to antimalarial drugs in vitro. Malar. J. 5:95. doi: 10.1186/1475-2875-5-95

Quignot, N., and Bois, F. Y. (2013). A computational model to predict rat ovarian steroid secretion from in vitro experiments with endocrine disruptors. PLOS ONE 8:e53891. doi: 10.1371/journal.pone.0053891

Rebelo, M., Sousa, C., Shapiro, H. M., Mota, M. M., Grobusch, M. P., and Hänscheid, T. (2013). A novel flow cytometric hemozoin detection assay for real-time sensitivity testing of Plasmodium falciparum. PLOS ONE 8:e61606. doi: 10.1371/journal.pone.0061606

Rieckmann, K. H., Campbell, G. H., Sax, L. J., and Mrema, J. E. (1978). Drug sensitivity of Plasmodium falciparum. An in-vitro microtechnique. Lancet 1 , 22-30. doi: 10.1016/S0140-6736(78)90365-3

Rieckmann, K. H., McNamara, J. V., Frischer, H., Stockert, T. A., Carson, P. E., and Powell, R. D. (1968). Effects of chloroquine, quinine, and cycloguanil upon 
the maturation of asexual erythrocytic forms of two strains of Plasmodium falciparum in vitro. Am. J. Trop. Med. Hyg. 17, 661-671. doi: 10.4269/ajtmh. 1968.17.661

Roncales, M., Vidal-Mas, J., Leroy, D., and Herreros, E. (2012). Comparison and optimization of different methods for the in vitro production of Plasmodium falciparum gametocytes. J. Parasitol. Res. 2012:927148. doi: 10.1155/2012/ 927148

Rothman, S. S. (2002). Lessons from the Living Cell: The Culture of Science and the Limits of Reductionism. New York, NY: McGraw-Hill.

Sanchez, B. A., Varotti, F. P., Rodrigues, F. G., and Carvalho, L. H. (2007). Validation of a Plasmodium falciparum parasite transformed with green fluorescent protein for antimalarial drug screening. J. Microbiol. Methods 69, 518-522. doi: 10.1016/j.mimet.2007.03.001

Sherman, I. W. (1961). Heterogeneity of lactic dehydrogenase in avian malaria (Plasmodium lophurae). J. Exp. Med. 114, 1049-1062. doi: 10.1084/jem.114.6. 1049

Sherman, I. W. (1977). Transport of amino acids and nucleic acid precursors in malarial parasites. Bull. World Health Organ. 55, 211-225.

Sherman, I. W. (1998). "Carbohydrate metabolism in asexual stages," in Malaria: Parasite Biology, Pathogenesis, and Protection, ed. I. W. Sherman (Washington, DC: ASM Press), 135-144.

Sinha, S., Medhi, B., and Sehgal, R. (2014). Challenges of drug-resistant malaria. Parasite 21, 61. doi: 10.1051/parasite/2014059

Si-Tayeb, K., Noto, F. K., Nagaoka, M., Li, J., Battle, M. A., Duris, C., et al. (2010). Highly efficient generation of human hepatocyte-like cells from induced pluripotent stem cells. Hepatology 51, 297-305. doi: 10.1002/hep. 23354

Slater, A. F., Swiggard, W. J., Orton, B. R., Flitter, W. D., Goldberg, D. E., Cerami, A., et al. (1991). An iron-carboxylate bond links the heme units of malaria pigment. Proc. Natl. Acad. Sci. U.S.A. 88, 325-329. doi: 10.1073/pnas. 88.2.325

Smalley, M. E. (1977). Plasmodium falciparum gametocytes: the effect of chloroquine on their development. Trans. R. Soc. Trop. Med. Hyg. 71, 526-529. doi: 10.1016/0035-9203(77)90149-3

Smilkstein, M., Sriwilaijaroen, N., Kelly, J. X., Wilairat, P., and Riscoe, M. (2004). Simple and inexpensive fluorescence-based technique for high-throughput antimalarial drug screening. Antimicrob. Agents Chemother. 48, 1803-1806. doi: 10.1128/AAC.48.5.1803-1806.2004

Sriwilaijaroen, N., Kelly, J. X., Riscoe, M., and Wilairat, P. (2004). Cyquant cell proliferation assay as a fluorescence-based method for in vitro screening of antimalarial activity. Southeast Asian J. Trop. Med. Public Health 35, $840-844$.

Stojiljkovic, I., Evavold, B. D., and Kumar, V. (2001). Antimicrobial properties of porphyrins. Expert Opin. Investig. Drugs 10, 309-320. doi: 10.1517/13543784. 10.2.309

Stone, W. J., Churcher, T. S., Graumans, W., van Gemert, G. J., Vos, M. W., Lanke, K. H., et al. (2014). A scalable assessment of Plasmodium falciparum transmission in the standard membrane-feeding assay, using transgenic parasites expressing green fluorescent protein-luciferase. J. Infect. Dis. 210, 1456-1463. doi: 10.1093/infdis/jiu271

Sullivan, A. D., and Meshnick, S. R. (1996). Haemozoin: identification and quantification. Trends Parasitol. 12, 161-163. doi: 10.1016/0169-4758(96) 40001- 1

Sung, J. H., Esch, M. B., and Shuler, M. L. (2010). Integration of in silico and in vitro platforms for pharmacokinetic-pharmacodynamic modeling. Expert Opin. Drug Metab. Toxicol. 6, 1063-1081. doi: 10.1517/17425255.2010. 496251

Tanaka, T. Q., Dehdashti, S. J., Nguyen, D. T., McKew, J. C., Zheng, W., and Williamson, K. C. (2013). A quantitative high throughput assay for identifying gametocytocidal compounds. Mol. Biochem. Parasitol. 188, 20-25. doi: 10.1016/ j.molbiopara.2013.02.005
Tanaka, T. Q., and Williamson, K. C. (2011). A malaria gametocytocidal assay using oxidoreduction indicator, alamarBlue. Mol. Biochem. Parasitol. 177, 160-163. doi: 10.1016/j.molbiopara.2011.02.005

Tekwani, B. L., and Walker, L. A. (2005). Targeting the hemozoin synthesis pathway for new antimalarial drug discovery: technologies for in vitro beta-hematin formation assay. Comb. Chem. High Throughput Screen. 8, 63-79. doi: 10.2174/ 1386207053328101

Trager, W., and Jensen, J. B. (1976). Human malaria parasites in continuous culture. Science 193, 673-675. doi: 10.1126/science.781840

Tripathi, A. K., Gupta, A., Garg, S. K., and Tekwani, B. L. (2001). In vitro betahematin formation assays with plasma of mice infected with Plasmodium yoelii and other parasite preparations: comparative inhibition with quinoline and endoperoxide antimalarials. Life Sci. 69, 2725-2733. doi: 10.1016/S00243205(01)01349-2

Tripathi, A. K., Khan, S. I., Walker, L. A., and Tekwani, B. L. (2004). Spectrophotometric determination of de novo hemozoin/betahematin formation in an in vitro assay. Anal. Biochem. 325, 85-91. doi: 10.1016/j.ab.2003.10.016

van der Kolk, M., De Vlas, S. J., Saul, A., van de Vegte-Bolmer, M., Eling, W. M., and Sauerwein, R. W. (2005). Evaluation of the standard membrane feeding assay (SMFA) for the determination of malaria transmission-reducing activity using empirical data. Parasitology 130, 13-22. doi: 10.1017/S0031182004006067 van Vianen, P. H., Thaithong, S., Reinders, P. P., van Engen, A., van der Keur, M., and Tanke, H. J. (1990). Automated flow cytometric analysis of drug susceptibility of malaria parasites. Am. J. Trop. Med. Hyg. 43, 602-607. doi: 10.4269/ajtmh.1990.43.602

van Vianen, P. H., van Engen, A., Thaithong, S., van der Keur, M., Tanke, H. J., van der Kaay, H. J., et al. (1993). Flow cytometric screening of blood samples for malaria parasites. Cytometry 14, 276-280. doi: 10.1002/cyto.990140307

Waki, S., Tamura, J., Jingu, M., Adachi, M., and Suzuki, M. (1986). A new technique for drug susceptibility tests for Plasmodium falciparum by ethidium bromide fluoroassay. Trans. R. Soc. Trop. Med. Hyg. 80, 47-49. doi: 10.1016/00359203(86)90192-6

Wein, S., Maynadier, M., Van Ba, C. T., Cerdan, R., Peyrottes, S., Fraisse, L., et al. (2010). Reliability of antimalarial sensitivity tests depends on drug mechanisms of action. J. Clin. Microbiol. 48, 1651-1660. doi: 10.1128/JCM.02250-09

Weisman, J. L., Liou, A. P., Shelat, A. A., Cohen, F. E., Guy, R. K., and DeRisi, J. L. (2006). Searching for new antimalarial therapeutics amongst known drugs. Chem. Biol. Drug Des. 67, 409-416. doi: 10.1111/j.1747-0285.2006.00391.x

Wernsdorfer, W. H., and Kouznetsov, R. L. (1980). Drug-resistant malariaoccurrence, control, and surveillance. Bull. World Health Organ. 58, 341-352.

Wernsdorfer, W. H., and Payne, D. (1988). "Drug sensitivity tests in malaria parasites," in Malaria: Principles and Practice of Malariology, eds W. H. Wernsdorfer and I. A. McGregor (Edinburgh: Churchill Livingstone), 1765-1800.

WHO (2016). World Malaria Report 2016. Available at: http://www.who.int/ malaria/publications/world-malaria-report-2016/report/en/

Yoon, M., Campbell, J. L., Andersen, M. E., and Clewell, H. J. (2012). Quantitative in vitro to in vivo extrapolation of cell-based toxicity assay results. Crit. Rev. Toxicol. 42, 633-652. doi: 10.3109/10408444.2012.692115

Conflict of Interest Statement: The authors declare that the research was conducted in the absence of any commercial or financial relationships that could be construed as a potential conflict of interest.

Copyright (c) 2017 Sinha, Sarma, Sehgal and Medhi. This is an open-access article distributed under the terms of the Creative Commons Attribution License (CC BY). The use, distribution or reproduction in other forums is permitted, provided the original author(s) or licensor are credited and that the original publication in this journal is cited, in accordance with accepted academic practice. No use, distribution or reproduction is permitted which does not comply with these terms. 